\title{
Approach to the Influence of the Terrestrial Magnetic Field on the Human Health
}

\author{
Diego de Jesús Alamino Ortega ${ }^{1}$, Yenile Aguilar Rodríguez ${ }^{1}$, Oliverio del Castillo Morejón ${ }^{2}$ \\ ${ }^{1}$ Professional Training Department, Municipal University Center, Matanzas University, Matanzas, Cuba \\ ${ }^{2}$ English Language Department, Medical Sciences Faculty, Medical Sciences University of Matanzas, Matanzas, Cuba
}

Email address:

diego.alamio@umcc.cu(D.de J. A. Ortega),yenile.aguilar.umcc.cu(Y. A. Rodríguez), odelcastillo.mtz@infomed.sld.cu(O.del C. Morejón)

\section{To cite this article:}

Diego de Jesús Alamino Ortega, Yenile Aguilar Rodríguez, Oliverio del Castillo Morejón. Approach to the Influence of the Terrestrial Magnetic Field on the Human Health. Rehabilitation Sciences. Vol. 3, No. 2, 2018, pp. 28-32. doi: 10.11648/j.rs.20180302.11

Received: November 1, 2017; Accepted: January 26, 2018; Published: April 16, 2018

\begin{abstract}
At the present times, people life and work into concrete buildings, and it has been reported that these structures decrease the earth's magnetic field, what is associated with human health affections, which become these type of reinforced concrete constructions into a potentially factor of environmental contamination. In this paper the authors, with a simple procedure, determine the possible attenuation of the terrestrial magnetic field by different types of construction, and report the results. To study the possible relation among certain health sufferings, attributed to the lack of magnetic field, so called Syndrome of Magnetic Field Deficiency, a survey was carry out trying to establish the relationships: type of constructionhealth affection. Considering the results obtained, arguments are given in favor of the application of magnetic therapies in the rehabilitation of some health sufferings.
\end{abstract}

Keywords: Lack of Earth's Magnetic Field, Reinforced Concrete Buildings, Human Health, Magnetic Therapies Rehabilitation

\section{Introduction}

The Earth is an immense imam and the life emerged and was developed under the influence of the terrestrial magnetic field, for what is considered that the geomagnetic local variations, in time and space, should bring alterations to the man's health $[1,2,3]$. As the normal condition of the existence of human beings is under the influence of the Earth's magnetic field it is logical that there is interest in studying this possible relationship. To study the influence of the magnetic field in the human health, has had several purposes for the authors, one of them was to determine, by means a simple method, the attenuation of the terrestrial magnetic field, that offers the reinforced concrete constructions, that prevail at the present time, and which become these type of concrete constructions, into a potential factor of environmental contamination, as others that take place caused by the current conditions of life on the planet. Another subject was to study the possible relation among the lack of terrestrial magnetic field and certain sufferings of the health, by means of a survey, which could justify the called Syndrome of Deficiency of Magnetic Field [4], and it may be considered as an epidemiology risk. As a last topic the authors offer arguments in favor of the application of magnetic therapies in the rehabilitation of some health sufferings.

\section{Method}

Determination of the Horizontal Component of the Terrestrial Magnetic Field

In order to determine the horizontal component of the terrestrial magnetic field a simple procedure was used, for which instruments and devices were needed; these instruments and devices can be obtained in any educational laboratory of physics: a direct supply electric current with output among $0-50 \mathrm{~V}$, an ammeter, a coil of wide radio (coil of Helmholtz with 320 loops) for to place inside of it a magnetic compass with a graduate scale, a commutator, a switch, and a rheostat, connected and disposed in the way that is indicated in the diagram of the annex 1.

To begin the determination, the magnetic compass is placed in such way that the direction of the terrestrial magnetic field stays in perpendicular position of the coil. Starting from here the work consists of passing electric current by the coil, superposing the magnetic field of it to the 
terrestrial magnetic field, and the magnetic needle will be forced to point in the direction of the resultant field. Varying the electric current that circulates for the coil, will vary the orientation of the magnetic needle, and will be obtained a set pairs values of the electric current (I) and of the deviation angle of the magnetic needle $(\theta)$. The angle can be determined through the average obtained when is measured in two opportunities the deviation of the magnetic needle, as a result of the inversion through the commutator of the electric current direction.

The formula that was used for the calculations is the following:

$$
B_{t h}=\frac{N I \mu_{0}}{2 R \tan \theta}
$$

Where: $\mathrm{B}_{t h}$ : horizontal component of the terrestrial magnetic field

$\mathrm{N}$ : number of loops in the coil

$\mu_{0}$ : magnetic permeability of the vacuum

$\mathrm{R}$ : the coil radio

$\theta$ : deviation angle of the magnetic compass

I: electric current

The determinations of the horizontal component of terrestrial magnetic field were carried out under the following conditions:

a) Outdoors

b) Inside a masonry house with tiles roof

c) Inside a masonry house and reinforced concrete roof

d) Inside the Physics laboratory of reinforced concrete

e) Inside a reinforced concrete building

The magnitude of the horizontal component of the terrestrial magnetic field, were obtained displacing the same equipment to the different locations, and the measurements were carried out by the same investigators.

\section{Results}

Results that were obtained by the authors are reporting below:

- In all the cases was made an adjustment of the curve I vs $\tan \theta$, obtained a coefficient of superior correlation to $99 \%$.

- The values of $\mathrm{B}_{\text {th }}$ (horizontal component of the terrestrial magnetic field) measured were the following:

a) Outdoors (30.9 \pm 0.3$) \mu \mathrm{T}$

b) Masonry house with tiles roof $(28.8 \pm 0.3) \mu \mathrm{T}$

c) Masonry house and reinforced concrete roof (27.1 \pm 0.3) $\mu \mathrm{T}$

d) Physics Laboratory (reinforced concrete) $(18.7 \pm 0.3)$ $\mu \mathrm{T}$

e) Reinforced concrete buildings (20.2 \pm 0.3$) \mu \mathrm{T}$

As a referential data, because it was not the purpose to determine the real value (absolute) of B for Cuba, in Spain [5], with a high latitude in comparison to the Cuba latitude, it is reported $25 \mathrm{~T}$ for the horizontal component of the terrestrial magnetic field. Taking into consideration the results obtained in the present work, the reinforced concrete structures produce a decreasing effect of the terrestrial magnetic field until approximately up to a $40 \%$. This confirms that this type of structure shields from the terrestrial magnetic field.

\section{Discussion}

\subsection{Possible Influence of the Decreasing of the Terrestrial Magnetic Field on Human Health}

The exposure to intense magnetic fields can affect the human health and the World Health Organization (WHO) has dictated norms for the personnel's protection that works under these conditions [6]. On the other hand the National Aeronautics and Space Administration (NASA) have considered like one of the possible affections that the astronauts can suffer in the space is the lack of magnetic field $[7,8]$, therefore there must be a relationships between human health and magnetic field. About the affectations by lack of magnetic field, another aspect is what the magnetic field can protect from the radiations coming from, for example, solar storms.

Through a bibliographical research, were extracted affections to health that had been considered in relation with the influence of the magnetic field $[1,3,4,10]$, and was made the survey that is reported in the annex 2 , which tries to relate the type of housing with the affection of health that is associated with the lack of magnetic field. This survey was applied by the investigators to 148 patients of different sexes, ages and races in doctor's office numbers 34 and 35 in Jagüey Grande south area, Matanzas province, Cuba, whose results are showing in the chart of the annex 3 .

It can be appreciated in the annex 3 at first sight, from percentage values obtained; that the patients that reside in the reinforced concrete buildings are more affected for health sufferings wich are related with the influence of the magnetic field. At the same time these structures are those that shield us more of the terrestrial magnetic field. In second place, for percentage, are the people that are living in houses with roof reinforced concrete and these houses are in turn second in the scale that have relation with the decreasing effect of the terrestrial magnetic field.

If is analyzed the occurrence of different affections we will see that not have the same incidence, the most significant are the joint pains, anxiety and the circulation of the blood, that highlight values near to $50 \%$, in the population that are living in reinforced concrete buildings, and shown equally high number for the residents in houses with reinforced concrete roof, decreasing significantly in the other cases. It is common to find in the reports of application of magnetic therapies those that are used for the treatment of joint pains.

Another part of the present paper consisted on trying to relate the type of construction of the work center with the health affections. For this work were interviewed 148 persons, from them 119 were workers, 2 were students, and 
27 were housewives. Of this analysis a clear dependence is not observed between health affections and type of construction of the work center, although in some cases certain tendencies can be appreciated. It is supposed that these results are due to a few of workers remain long time in the same work center. It should be considered that another variable, object of questions to the patients was the stay time in the construction type.

\subsection{About the Magnetic Therapies (Electromagnetic Therapies)}

In the scientific and non-scientific literature it can be found that magnetism has been used to cure diseases of all kinds, since ancient times. In these practices there has been mysticism and obscurantism. There are also practices that use an obscure and ambiguous scientific terminology without a scientific basis or method, which has been described as pseudoscientific practices [11]. Devices of doubtful effectiveness are sold and only reach to offer an effect placebo, something similar happens with the magnetic treatment of water, where erroneously it is spoken about "magnetized water" without taking into account that water is not a ferromagnetic material [12], and it is attributed to the magnetic treated water, healing properties.

On the other hand, the pineal gland that is the gland that secrete melatonin, it is considered as a magnetic sensory and by means of applications of magnetic fields of the $\mathrm{pT}$ order to this gland, surprising results were reported, specifically for the cure in the case of some illnesses like: migraines, Parkinson's disease, osteoporosis, multiple sclerosis and spontaneous abortion [13]. Recent research has found that the human eye contains a light-sensitive compound that can sense the planet's magnetism. The study was presented by the Medical School of the University of Massachusetts, in the United States [14]. These are arguments that speak in favor of the interaction of the magnetic field, or more generally, the electromagnetic field, with the substance.

The Dr. Nakagawa, father of the modern magnetic therapy, affirms that nowadays the mankind is suffering a Syndrome of Deficiency Magnetic Field as a consequence of the ecological imbalance that suffers the Earth, for him is not strange that the modern man suffers diverse health dysfunctions, physical and psychological, caused by live between the steel and the reinforced concrete, that isolated him of the terrestrial magnetic field.

Through of the reported in the literature, in shortly synthesis, has been treated to summarize in the previous paragraphs, arguments in favor of the magnetic therapies which may be united to the modest results obtained in this paper, to turn attention to the application of magnetic therapies in the measure of replace the deficiency of terrestrial magnetic field or to recommend at least to remain to outdoors for the recovery some affections.

\section{Conclusions}

- It has been determined with simple equipment and with an acceptable grade of reliability that the reinforced concrete structures, with which are manufactured the most modern constructions, produce a significantly decreasing effect of the terrestrial magnetic field, approximately $40 \%$.

- Although multiple factors can influence in the appearance of health affections, for example, the alimentation conditions, the environmental contamination and other which must be discriminated against in deeper studies, it is appreciated in the survey results to that exists a tendency to increase the percentage of ailments in the case of decreasing of terrestrial magnetic field. This should be taking into account in relation with certain ailments, characteristic of professional illnesses.

- It is argues in favour of the application of magnetic therapies, something that has charged a lot of relevance and may be a means of replacing the lack of terrestrial magnetic field, whenever it is carried out a meticulous study of the patient ailment, and it is selected appropriately the work parameters for the electromagnetic field that will be used in the patient rehabilitation specially: intensity and frequency

\section{Appendix}

Appendix 1

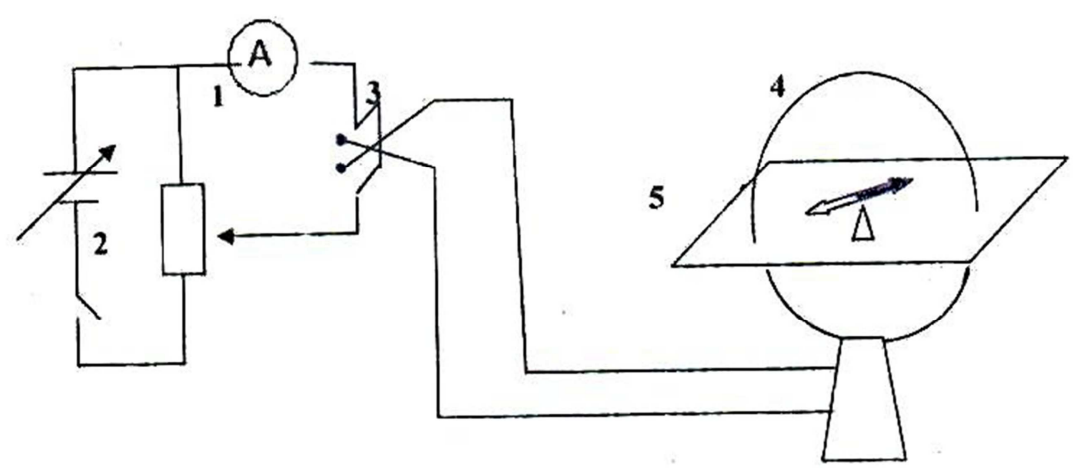

Key: Ammeter 1, direct supply electric current 2, commutator 3, Helmholtz coil 4, magnetic compass with a graduate scale 5

Figure 1. Experimental disposition. 


\section{Appendix 2}

I- Model for the interview

Name

Address

Age Sex Race

Occupation Time of permanency Characteristics of the installation

Illnesses that is suffering or that has been suffered Time

1 - Join pain

2 - Anxiety

3 - Blood Circulation

4 - Insomnia

5 - Headache

6 - Depression

7 - Psychiatric

8 - Lumbago

9 - Osteoarthritis

10 - Constipation

11 - Rheumatism

12 - Sciatic

13 - Alopecia

14 - Acne

Type of construction

A- Reinforced concrete Building

B - Masonry and concrete covered

C - Masonry and fiber cement

D - Masonry and tiles

A - Wood and tiles

F - Wood and guano

\section{Appendix 3}

Table 1. Health affections and patient per housing type.

\begin{tabular}{|c|c|c|c|c|c|c|}
\hline \multirow[t]{2}{*}{ Health affections } & \multicolumn{6}{|c|}{$\%$ of patient per housing type } \\
\hline & Type 1 & Type 2 & Type 3 & Type 4 & Type 5 & Type 6 \\
\hline Joinpain & 56.4 & 39 & 12.5 & 28.1 & 14.9 & 5.1 \\
\hline Anxiety & 53.2 & 39 & 12.5 & 9.8 & 10.6 & 5.1 \\
\hline Blood Circulation & 48.3 & 31.8 & 25 & 9.4 & 14.9 & 5.1 \\
\hline Insomnia & 38.7 & 16.3 & 12.5 & 18.9 & 4.3 & ---- \\
\hline Headache & 37 & 26.3 & 25 & 18.7 & 21.3 & 10.3 \\
\hline Depression & 35.4 & 23 & 25 & 18.7 & 6.4 & 5.1 \\
\hline Psychiatrics & 30.6 & 27.2 & 12.5 & 15.6 & 12.8 & 5.1 \\
\hline Lumbago & 27.4 & 20 & 12.5 & 12.5 & 4.3 & 10.3 \\
\hline Osteoarthritis & 22.5 & 22.7 & ---- & 37.5 & 12.8 & 5.1 \\
\hline Rheumat. & 22.5 & 18.1 & 9.4 & --- & 8.5 & 15 \\
\hline Sciatic & 9.6 & 9 & 12.5 & 6.2 & 4.3 & --- \\
\hline Alopecia & 8 & 9 & 12.5 & 6.2 & 4.3 & --- \\
\hline Acne & --- & 36 & --- & ---- & ---- & ---- \\
\hline
\end{tabular}

Key:

Housing type 1: Building House of reinforced concrete.

Housing type 2: House with masonry walls and reinforced concrete roof.

Housing type 3: House with masonry walls and fiber cement roof

Housing type 4: House with masonry and tiles roof

Housing type 5: House with wood walls and tiles roof.

Housing type 6: House with wood walls and guano roof. 


\section{References}

[1] Pérez, A. La Naturaleza el hombre y el magnetismo, Rev. Cubana de Medicina General Integral. 2002; 18 (1):73-5.

[2] Saez, A, El magnetismo terrestre influye en nuestra salud, Ecoportal y Ambiente y Sociedad, www.ecoportal.net, consulted 20 de octubre 2017.

[3] Bardasano, J. L. "Electromagnetismo, glándula pineal y salud pública", Ponencia presentada en las Jornadas "Campos electromagnéticos, salud pública y laboral" Organizado por CCOO Madrid Diciembre 2002. Consult in www.medicionderadiaciones.com/bardasano.pdf.

[4] Nakagawa, K. Magnetic Field Deficiency Syndrome and Magnetic Treatment 4data.ca/ottawa/archive/health/biomagnetic.html.

[5] Medida de la intensidad del campo magnético. Consult in www.sc.ehu.es/sbweb/fisica/elecmagnet/.../medida_campo/me dida_campo.htm.

[6] Campos electromagnéticos y salud pública, Nota descriptiva No. 322 junio 2007, consult in: www.who.int/pehemf/publications/facts/fs322/es.

[7] Consult in http://www.novaciencia.com/2008/10/02/peligranastronautas-por-falta-de-campo-magnetico-terrestre/.
[8] Pérez, G. Magnetoterapia, Ediciones Lea SA, Buenos Aires, ISBN 978-987-634-941-3, 2013, Web: www.edicioneslea.com.

[9] Pérez, G. Campos Magnéticos en salud. Consult in www.mantra.com.ar/contterapiasalternativas/camposmagnetic osensalud.htm.

[10] Martín, J. y García, J. Efectos y aplicaciones de la magnetoterapia www.sld.cu/galerias/pdf/sitios/.../efectos_y_aplicaciones_de_1 a_magnetoterapia.pdf.

[11] González, A. Magnetismo y seudociencia en la medicina, Revista Cubana de Física Vol. 20, No. 1, 2003.

[12] Alamino, D. de J. y Aguilar, Y. Tratamiento magnético de agua (TMA): Teorías y efecto de un magnetizador, CD Monografías 2015, Universidad de Matanzas "Camilo Cienfuegos", ISBN: 978 - 959 - 16 - 2986 - 9 .

[13] Sandy, R. Magnetic fields in the therapy of Parkinsonism, Int. J. Neurosci. 3-4, No. 68, oct 1992, p. 209-235.

[14] El ojo humano tiene sustancias que pueden actuar como una brújula, BBC Ciencia, consult in: http://www.bbc.com/mundo/noticias/2011/06/110622_humano s_magnetismo_brujula_m. 